\title{
An Efficient Synthesis of Thiophene/Pyrrole-Fused Crown Ethers Using Mitsunobu Reaction for Potential Application to Sensory Electroactive Polymers
}

\author{
Joongchul Kim, ${ }^{\dagger}$ Daehyun Yoon, Sang Hee Lee, ${ }^{\dagger}$ Seokbeom Ko, Youn-Sik Lee, ${ }^{\ddagger}$ and Kyukwan Zong ${ }^{*}$ \\ ${ }^{\dagger}$ Department of Chemistry, Kunsan National University, Kunsan 573-701, Korea \\ Instifute of Science Education, Division of Science Education, Chonbuk National University, Jeonin 561-756, Korea \\ "E-mail: kzong@chonbukac.kr. \\ "Department of Chemical Engineering, Chonbut National University, Jeonji 561-756, Korea \\ Received September 5, 2006
}

Key Words : Thiophene, Pyrrole, Conjugated polymer, Crown ether, Mitsunobu reaction

Recently it has been very attractive topic for scientists to use conjugated polymers (CPs) towards sensory materials because of their transport properties such as electrical conductivity or fluorenscence. Conjugated polymers (CPs) may offer a great deal of opportunities to couple analytereceptor interactions, as well as nonspecific interactions, into observable or transducible responses. Conjugated polymerbased sensors may enjoy several advantages over small molecule-driven sensors owing to their better stability and much amplified sensitivity. ${ }^{1}$ With great potential of conjugated polymers having sensing functionality to be used as advanced materials, it is important to build up a variety of conjugated polymers that have various functions. It may be no doubt that one of the most intensively investigated polymer as chemical sensors are crown ether-based conjugated polymers. However, it is not always easy to synthesize crown-ether tethered monomers or polymers because crownether ring closing reactions suffer from mostly low yield, high dilute reaction conditions, and introduction of templateassisted methods. Traditionally, crown ethers have been synthesized by reaction of a diol with a dihalo or disulfonyl group terminated counterpart under Williamson condition but this route usually suffers from the low yield due to a variety of by-product fornations. ${ }^{2}$ Another route that has been developed more recently is template-assisted method where a cation is used for complex formation with a polyethylene glycol to help ring-closing reaction more effectively but this route may be not appropriate for multi-gram scale synthesis due to high dilution reaction conditions and uses of templates. ${ }^{3}$ Here we report an efficient and simple synthetic route that is generally applicable for synthesis of thiophene or pynrole-fused crown ethers from moderate to good yield.

Our previous study revealed that 3,4-ethylenedioxythiophene (EDOT), 3,4-propylenedioxythiophene (ProDOT), and their derivatives were efficiently synthesized through Mitsunobu chemistry as a key step with moderate to good yield. ${ }^{4}$ This method usually enjoys several advantages over Williamson condition such as no use of halo-compound, very mild reaction condition $\left(25-60^{\circ} \mathrm{C}\right)$, and short reaction time (mostly less than $2 \mathrm{~h}$ ). In connected with those results, we envisioned that thiophene or pyrrole-fused crown ethers that are considered as important monomers for CPs might also be synthesized under similar protocol employed by our previous studies.

\section{Results and Discussions}

It was already disclosed in our previous study that the reaction of the 3,4-dihydroxythiophene derivative $\mathbf{1}$ and ethylene glycol under Mitsunobu condition gave the cyclized product 8 in high yield $(90 \%)$. A series of ethylene glycol derivatives with short chains through long chains were employed in the reaction whether this protocol can be extended to synthesize thiophene-fused crown ethers. Initially, the reaction of diethylene glycol and $\mathbf{1}$ under standard Mitsunobu condition (dead, $\mathrm{PPh}_{3}$, ether at room temperature, $2 \mathrm{~h}$ ) was investigated and the crown ether 9 was obtained in $55 \%$ isolated yield. Then, phosphine reagents (tributylphosphine and triphenylphosphine), solvents (ether, $\mathrm{THF}$, dichloromethane), and reaction temperature were varied in the reaction in order to find better reaction condition and the reaction for 9 was improved to $75 \%$ yield under the condition only replaced by THF (dead, $\mathrm{PPh}_{3}$, and dead at room temperature for $2 \mathrm{~h}$ ). THF turned out a choice of solvent and increasing reaction temperature tended to decrease product yield. Varying phosphine reagent from triphenylphosphine to tributylphosphine did not affect much on the reaction although the use of tributylphosphine was a bit favored over triphenylphosphine in some cases. However, use of triphenylphosphine is much easy to handle and was chosen in this reaction.

Then the reactions proceeded by employing other chains of ethylene glycol derivatives, $\mathbf{4}$ and $\mathbf{5}$ that are only different in chain length. The reaction gave compounds, $\mathbf{1 0}$ and $\mathbf{1 1}$, in $65 \%$ and $54 \%$ respectively. These yields seem to be about moderate in common organic synthesis but must be highly promising in macrocyclization reactions if much simpler reaction condition over traditional ones was considered. Increasing ethylene glycol chains to pentaethylene glycol and hexaethylene glycol tended to give lower yield to $45 \%$ and $35 \%$ respectively and all compounds synthesized here are listed in Scheme 1. From a series of reactions, it is generally agreed that increasing chain length proportionally 


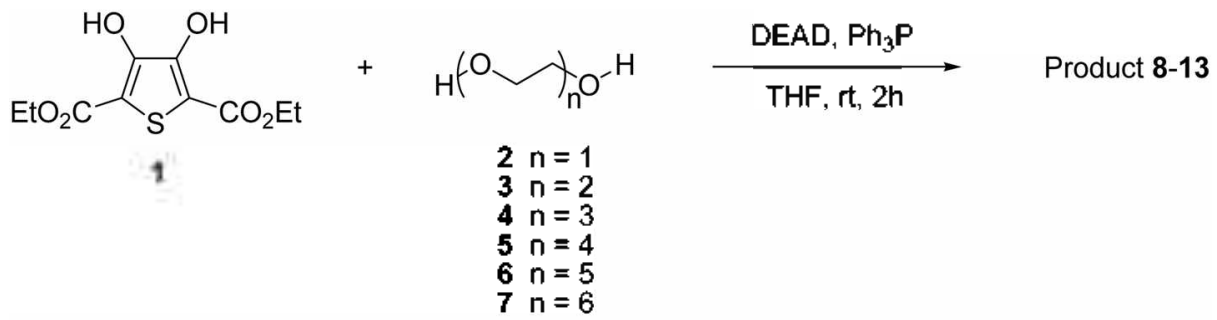

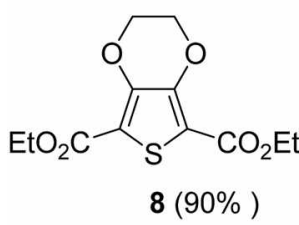

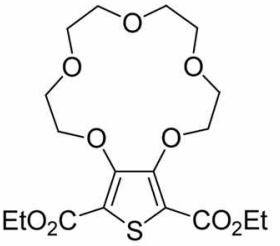

11 (54\%)
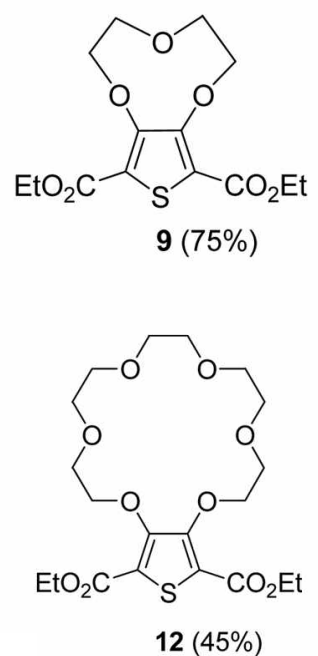<smiles>CCOC(=O)c1sc(C(=O)OCC)c2c1OCCOCCOCCO2</smiles><smiles>CCOC(=O)c1sc(OCC)c(OCC)c1OCCOCCOCCOCCOCCOCCO</smiles>

Scheme 1<smiles>CCOC(=O)c1c(O)c(O)c(C(=O)OCC)n1Cc1ccccc1</smiles>

14<smiles>CCOC(=O)c1c2c(c(C(=O)OCC)n1C)OCCOCCO2</smiles>

$15(60 \%)$<smiles>CCOC(=O)c1c2c(c(C(=O)OCC)n1C)OCCOCCOCCO2</smiles>

$16(55 \%)$<smiles>CCOC(=O)c1c2c(c(C(=O)OCC)n1C)OCCOCCOCCOCCO2</smiles>

$17(50 \%)$

Scheme 2

brings decrease in isolated yields. Especially the isolation of 13 was more demanding than that of other compounds due to its higher polarity that may be somewhat attributed to its low yield.

In order to demonstrate the scopes and limitations of this methodology, we applied this protocol to another diol 14 that has been served as an important starting material to synthesize a pyrrole analogue (EDOP; 3,4-ethylenedioxypyrrole) of EDOT. The EDOP has been known to have very low oxidation potential to undergo much easier oxidative polymerization to provide highly stable conducting polymer ${ }^{5}$ and be more bio-compatible than its thiophene analogue. ${ }^{6}$ So, 3,4-dioxypyrroles fused with crown ether can also be served as highly valuable monomers for similar purposes. The reactions of 14 with a series of ethylene glycol derivatives, 3,4 , and 5 under similar condition underwent smoothly to afford the cyclized products $15-17$ in $60 \%, 55 \%$, and $50 \%$ yield respectively (Scheme 2).

In order to demonstrate the usefulness of the intermediates, 11 was selected and further manipulated to a thiophenefused monomer according to the known procedures. Simply, hydrolysis and then decarboxylation of $\mathbf{1 1}$ afforded a 


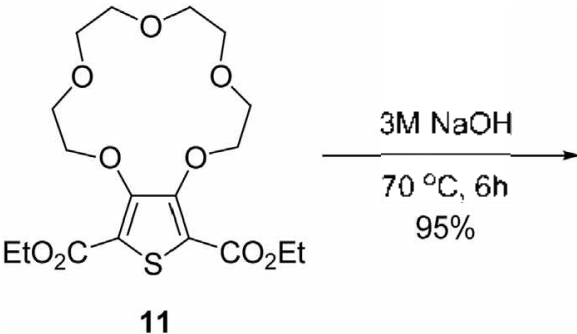

11
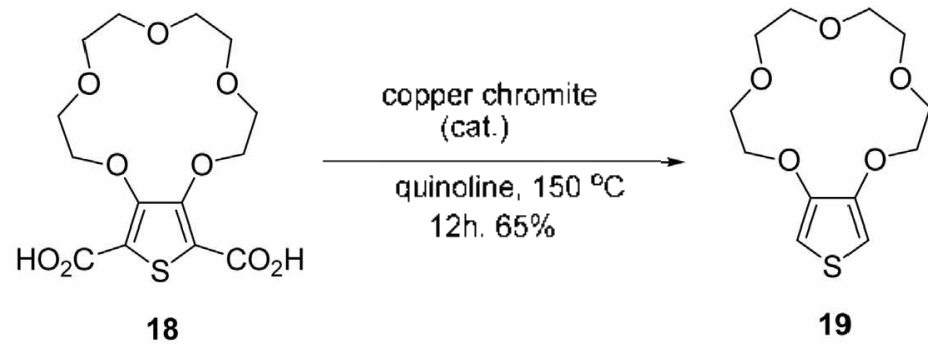

19

Scheme 3

thiophene-fused crown ether $\mathbf{1 5}$ in good yield (Scheme 3). Further studies of polymerization of 19 and other monomers and their uses as electroactive ion-sensing polymers will be reported in another paper.

\section{Experimental Section}

General Procedure for Preparation of 8-13 and 15-17: To the reaction mixture of $1(1.00 \mathrm{~g}, 4.38 \mathrm{mmol}), \mathrm{PPh}_{5}(2.40 \mathrm{~g}$. $8.77 \mathrm{mmol})$, and tri(cthylenc)glycol $(1.33 \mathrm{~g}, 8.77 \mathrm{mmol}$ ) in distilled TIFF was slowly added dicthyl arodicarboxylate (dead, $40 \%$ in toluene, $4.58 \mathrm{~g}, 10.54 \mathrm{mmol}$ ) with stirring at room temperature. The reaction mixture was stirred for $2 \mathrm{~h}$ and concentrated by rotary evaporator. The residue was diluted with $10 \mathrm{~mL}$ of ether and placed in refrigerator. Precipitated triphenylphosphine oxide was filered off and the resides was further concentrated and purified by column chromatography on silica gel. Spectroscopic dala of selected compounds; 9; ${ }^{\mathrm{H}} \mathrm{H} \mathrm{NR}\left(400 \mathrm{MHz}, \mathrm{CDCl}_{3}\right): \delta 1.36$ (t, $J=$ $7.0 \mathrm{~Hz}, 6 \mathrm{H}), 3.93(\mathrm{~m}, 4 \mathrm{H}), 4.33(\mathrm{q}, J=7.0,4 \mathrm{H}), 4.45(\mathrm{~m}$, $4 \mathrm{H}) ;{ }^{13} \mathrm{C} \mathrm{CMR}\left(100 \mathrm{MHz}, \mathrm{CDCl}_{3}\right): \& 14.28,61.21,73.35$, $74.36,117.78,153.57,160.55 ;$ HRMS (FI) ( ${ }^{1}$ ) calcd for $\mathrm{C}_{1+} \mathrm{H}_{18} \mathrm{O}_{7} \mathrm{~S} 330.0773$, found $330.0777 .12 ;{ }^{\prime} \mathrm{H}$ NMR $(400$ $\left.\mathrm{MHz}, \mathrm{CDCl}_{3}\right): \delta 1.36(\mathrm{t}, J=7.0 \mathrm{~Hz}, 6 \mathrm{H}), 3.55-3.80(\mathrm{~m}$, $12 \mathrm{H}), 3.85-3.93(\mathrm{~m}, 4 \mathrm{H}), 4.50-4.90(\mathrm{~m}, 8 \mathrm{H}) ;{ }^{13} \mathrm{C} \mathrm{NMR}(100$ $\left.\mathrm{MHz}, \mathrm{CDCl}_{5}\right): \delta 14.21,61.33,70.13,70.62,70.64,70.85$, $74.01,119.68,153.09,160.44$; HRMS (EI) (M') calcd for $\mathrm{C}_{20} \mathrm{H}_{30} \mathrm{O}_{13} \mathrm{~S}$ 462.1559, found 462.1559. 19; 'H NMR (400 $\left.\mathrm{MHz}, \mathrm{CDCl}_{3}\right): \delta 3.74(\mathrm{~s}, 8 \mathrm{H}), 3.88(\mathrm{~m}, 4 \mathrm{H}), 4.13(\mathrm{~m}, 4 \mathrm{H})$, 6.25 (s. $2 \mathrm{H}) ;{ }^{13} \mathrm{C} \mathrm{NMR}\left(100 \mathrm{MHz}, \mathrm{CDCl}_{3}\right): \delta 70.08,70.29$, $70.66,74.64,105,45,119.44$; HRMS (EI) (M') calcd for
$\mathrm{C}_{12} \mathrm{H}_{18} \mathrm{O}_{5} \mathrm{~S} 274.0875$, found 274.0862

Acknowledgements. This work was supported by Korea Research Foundation Grant (KRF-2004-003-C00134).

\section{References}

I. For review of conjugated polymer-based chemical stensors and conducting polymers; (a) Swager, T, . ., Ace. Chem, Res. 1998 , 31. 201, (b) MeQuade, D. T.; Pullen, A. F.; Swager, T, M. Chem. Rev 2000, 100, 25,37. (c) Henutbonk of Conductiong Polysters, $2^{\text {nd }}$ ed; Skotheim, T. A.; Elsenbaumer, R. L.: Rey'nolds, I. R., Eds.; Mareel Dekker: New York, 1998. For recent articles of conjugated polymer-based chemical sensors; (a) Ho. II.-A.; Boissinot M;

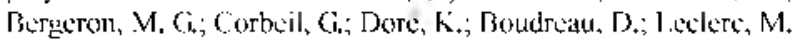
Ahgen: Chern. Int. Fd, 2002, 4I, 1548, (b) Gaylord, B. S.; I lecener,

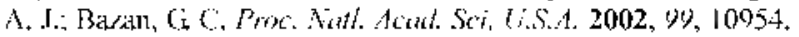
(c) Wang, S.; Liu, B.: Gaylerd, B. C. Bayan, C. C. Adt: Finct. Whter. 2003. 13, 463. (d) T.ju. B.; Gaylord. B. S.; Wang. S.; Baran, C. C.J. Am. Chem, Soc, 2003. 125, 6705. (c) J Juang. F,

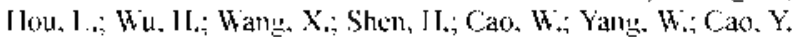
J. Am, Chem, Soc, 2004, 126, 9845. (1) 7hou, Gi: Qian, G; Ma, I..:

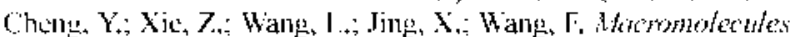
$2005,38,5416$.

2. The Chemistr of Ethers. Cronn Ethers. Hutroxy Groups and Their Sulfir Andognes. Part I; Palai, S. Fd.; John Wiley \& Sons.: 1980.

3. (a) Murashima, $T_{\text {; }}$ Uchilara $Y_{\text {; }}$ Wakamori, N.; Lno. II.; Oyawa.

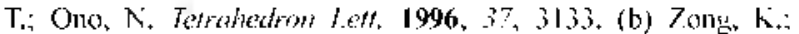
Reynolds. J. R. J. Org. Chem. 2001, 66, 6873.

4. Zong, K.; Luis, M.; Groenendaal, L. B.; Reytnolds, I. R. Chem. Commm. 2002, 21, 2498.

5. Schottland. P.; 7.ng. K.; Gaupp. C. I..; Thompson. B. C..;

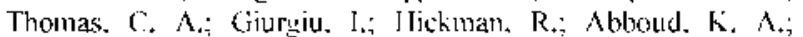
Reynolds, J. R. Hacromolec 1 les 2000, 33, 7051.

6. Thomas, C. A.: Zong, K.; Schouland, P.: Reynolds, J. R. Ach: Water: 2000, $12,222$. 